\title{
Investigation of potential cognition factors correlated to fire evacuation
}

\author{
Jingjing Yan, Gengen He, Anahid Basiri
}

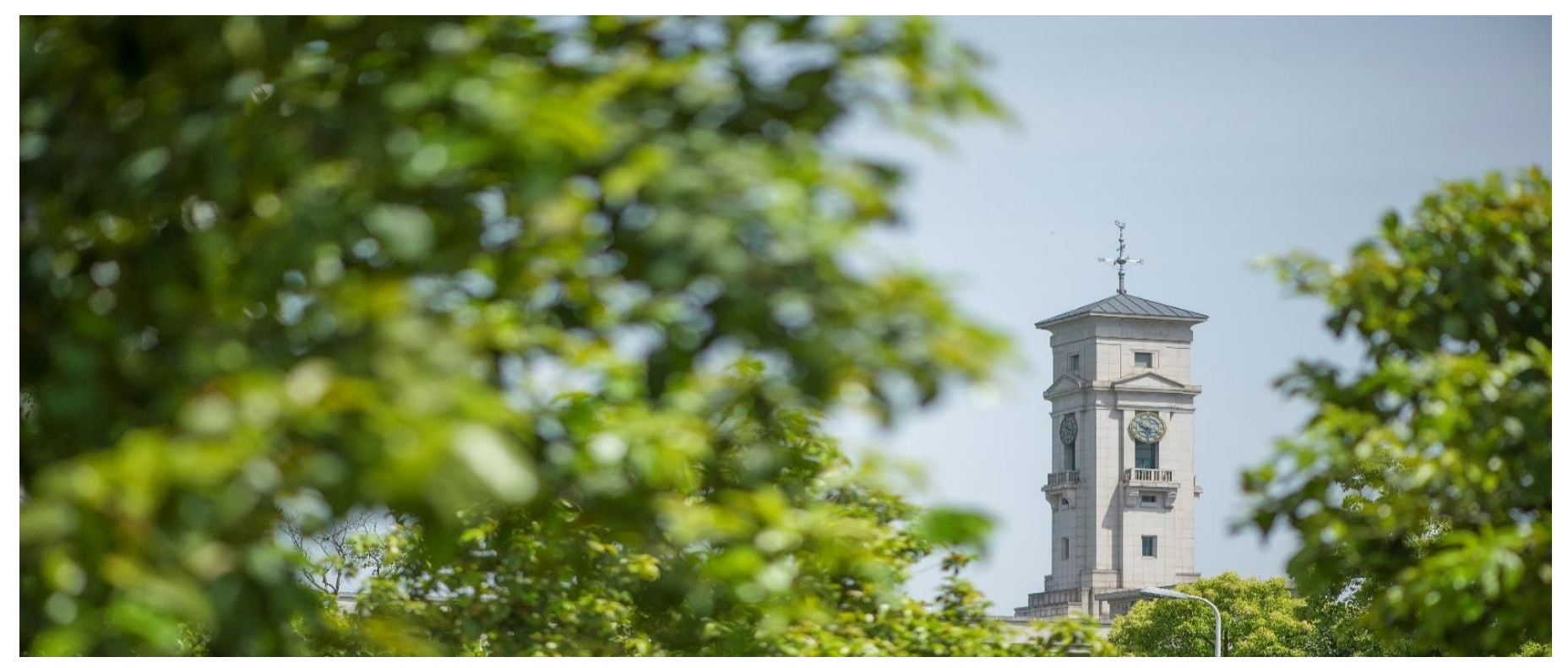


University of Nottingham Ningbo China, 199 Taikang East Road, Ningbo, 315100, Zhejiang, China.

First published 2020

This work is made available under the terms of the Creative Commons Attribution 4.0 International License:

http://creativecommons.org/licenses/by/4.0

The work is licenced to the University of Nottingham Ningbo China under the Global University Publication Licence:

https://www.nottingham.edu.cn/en/library/documents/research/global -university-publications-licence-2.0.pdf 


\title{
Investigation of Potential Cognition Factors Correlated to Indoor Fire Evacuation
}

\author{
Jingjing $\mathrm{Yan}^{1[0000-0003-4082-8438]}$, Gengen $\mathrm{He}_{0002-2399-1797]}^{1[0000-0001-7444-2846]}$, and Anahid Basiri ${ }^{2[0000-}$ \\ ${ }^{1}$ University of Nottingham Ningbo China, 315100, China \\ ${ }^{2}$ University College London, WC1E 6BT, London, UK \\ lncs@springer.com
}

\begin{abstract}
The design of a navigation system to support indoor fire evacuation depends not only on speed but also a relatively thorough consideration of the cognition factors. This study has investigated potential cognition factors which can affect the human behaviours and decision making during fire evacuation by taking a survey among indoor occupants in age of 20 s under designed virtual scenarios. It mainly focuses on two aspects of Fire Responses Performances (FRP), i.e. indoor familiarity (spatial cognition) and psychological stress (situated cognition). The collected results have shown that these cognition factors can be affected by gender and user height and they are correlated with each other in certain ways. It has also investigated users' attitudes to the navigation services under risky and non-risky conditions. The collected answers are also found to be correlated with the selected FRP factors. These findings may help to further design of personalized indoor navigation support for fire evacuation.
\end{abstract}

Keywords: Fire Response Performance, Indoor Spatial Cognition, Situated Cognition, Survey Analysis.

\section{$1 \quad$ Introduction}

The design of an indoor navigation system to support fire evacuation is not only based on the physical mobility (speed) of people, their responses to the fire also merits consideration [1]. The FRP is defined as the capability of an evacuee's perception and interpretation of the warning signs, and decision making for fire survival. The factors which affect the FRP can be divided into three categories from fire, human and building environments [1-3]. This study will more focus on the specific impacts from human and environments on the wayfinding aspect.

For the environmental factors of FRP, they can be divided into five classes [1, 4]. Among these classes, the effects from indoor familiarity and the satisfaction degree to the locations of existing indoor signs are investigated. The reason of selecting these two factors is due to that the unfamiliarity to the building context is also considered as a special disability [5-8]. Meanwhile, the decision making during a fire evacuation also depends on indoor familiarity as people prefer using familiar paths/exits for evacuation $[9,10]$. It can be relatively time consuming for floor plan discovery and 
escape route formulation with lower familiarity $[11,12]$.

For human factors of FRP, the psychological stress is one important personal characteristic during the evacuation, as it can impede people's cognition and response process, leading to irrational and uncontrolled behaviours [1, 8, 13-15]. This study mainly concentrates on the individual-level psychological effects, which include evacuation knowledge and experience, capability of observation and decision-making, as well as evacuation mobility $[1,3]$. It can be affected by human's psychological characteristics, e.g. gender, and specific environmental scenarios $[15,16]$.

Besides, the user attitudes to the smartphone-based navigation also plays an important role. It is considered one of the major challenges to the promotion of applying the designed fire emergency navigation system to a wide range of population. This study will investigate user responses to the navigation services under normal and extreme conditions.

This study aims to explore the user responses of the indoor familiarity, psychological stress, and attitude to the navigation services under the conditions of the designed scenarios in Sir Peters Mansfield Building (PMB) of University of Nottingham Ningbo China (UNNC). The user responses will be collected via survey by using designed questionnaire. The collected answers will then be used to analyse the correlations between participants' familiarity with the indoor environments and their intuitive psychological conditions with the bending postures. It also tries to study the potential causes of decision making during evacuation movement under the designed extreme cases.

\section{$2 \quad$ Methodology}

\subsection{Subjects and Study Area}

In order to evaluate the potential responses of participants in an environment that they are accustomed to, this study has selected the PMB building in UNNC as the test site and students who normally stay in this building as the volunteers, who are supposed to have more knowledge about its indoor structures.

The survey has been conducted among undergraduate students with an average age at 25.28 females and 22 males are recruited to take the survey. The majority of the anticipated female volunteers have a height in the range of $160 \sim 165 \mathrm{~cm}$ and their weights are in the range of 50 55kg. Meanwhile, the representative height and weight of male anticipants are in the range of $175 \sim 180 \mathrm{~cm}$, and $65 \sim 75 \mathrm{~kg}$ respectively. All the participated volunteers have a BMI (Body Mass Index) at a healthy stage (19.9 24.2). The involvement of these participants help to get rid of the effects from the overweight and age, which may introduces more physical variations [1, 17-20]. The overall process has been approved by the UNNC Institutional Review Board and all subjects has signed the written informed consent. 


\subsection{Involved Scenarios}

Indoor Familiarity This survey has selected three aspects to evaluate the degree of indoor familiarity of participants, which are:1)familiarity to the evacuation exits; 2)familiarity to the risky places; 3 )satisfaction to the installed guiding signs.

Psychological Stress when Using Bending Posture The reason of setting up this situation is due to the potential threats from smoke inhalation and growing fall risk when using a bending posture [21, 22]. This study will evaluate the user responses from three aspects when forcing to move under a bending posture: 1)cognition of the moving difficulty; 2)cognition of the nervousness; 3 )cognition of the speed reduction.

Attitude to the Navigation Services during Evacuation This study tries to identify potential problems, which needs to be considered and helps to provide corresponding suggestions in future improvements before providing customizable navigation services to the users. It will investigate the user attitudes from three aspects: 1)familiarity to the existing smartphone-based navigation; 2)willingness of following guidance service during the evacuation under non-risky conditions; 3)willingness of following guidance service under some extreme cases and corresponding decision time;

\section{$3 \quad$ Results and Analysis}

\subsection{Indoor Familiarity}

The majority of participated males $(54 \%)$ and females $(61 \%)$ have at least mid-level knowledge (' 3 to 4') of the locations of all exits. Among them, the male has a higher average familiarity (2.77) with the exits than the female (2.64) (Fig.1(a)). There is one male participant has the full familiarity with all the exits while there is none for female. For the familiarity of indoor risky places, though average level from both genders is relatively low, there are more male participants $(50 \%)$ have a relatively higher degree (' 3 to 5 ') than females (46\%) (Fig.1(b)). These may be partially explained by the satisfaction of indoor signs, as about half of the interviewed male students are relatively satisfied with the current setups of the indoor evacuation signs (with the high score as '4'), while for the female participants, it tend to have fewer people with similar degree of satisfaction (Fig.1(c)).

Height seems to be an important physical factor for indoor spatial cognitions. When analysing the data from user height and satisfaction degree to the indoor signs, it can be found that they are positively correlated with at least medium level $R$, which is about 0.311 for the females and 0.559 for the males (

Table 1 \& Table 2). In general, the satisfaction level keeps growing with user height except for the ' $170 \sim 175 \mathrm{~cm}$ ' female group. Moreover, this trend is more clear based on the males' data (Fig. 2). This also suggests that the height effects on the satisfaction level of indoor signs from the males are slightly significant than that from the females may be explained by the higher average height of male participants. Their 
higher average height may help them more easily recognize the existence of the indoor signs.

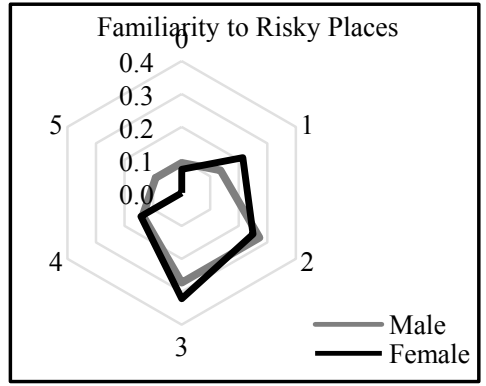

(a)

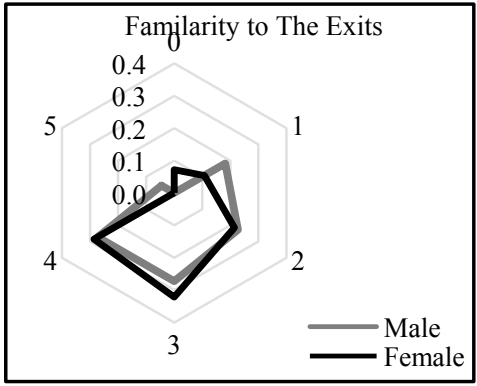

(b)

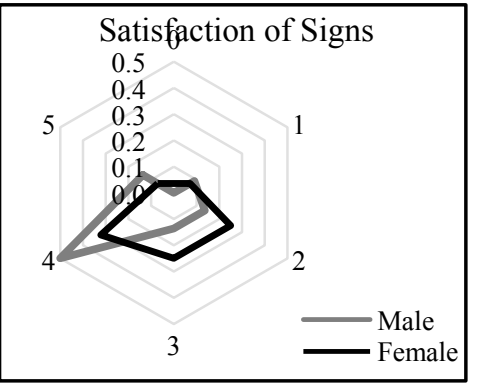

(c)

Fig.1. The distribution of user feedbacks of the familiarity to the indoor exits (a), risky places (b), and satisfaction of indoor signs (c) from lowest (0) to highest (5).

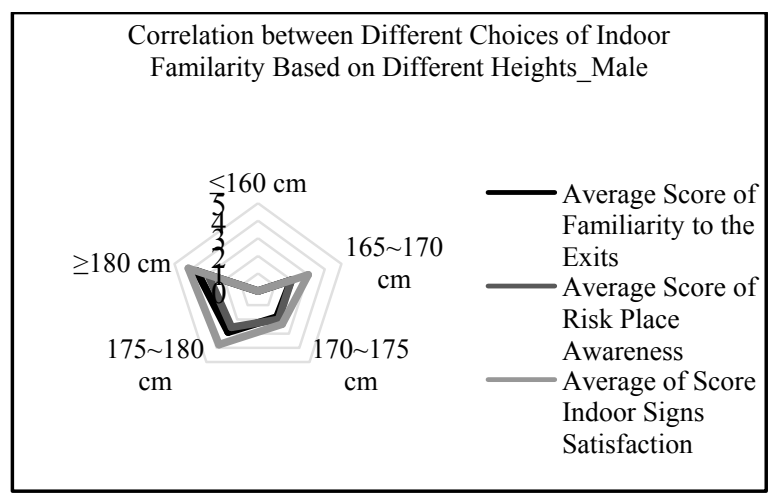

(a)

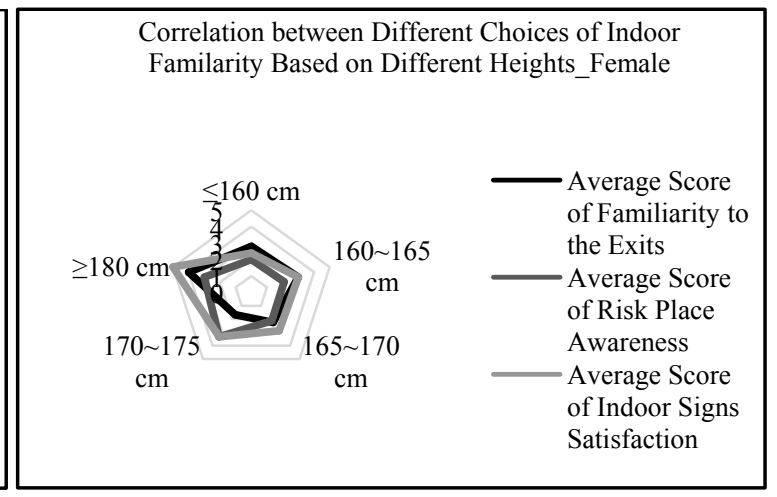

(b)

Fig. 2. The comparison of indoor familiarity with different heights of males (a) and females (b).

Meanwhile, the correlation between heights and familiarity to exits also suggests a similar conclusion as males' data show a stronger positive relationship $(R=0.561)$ between these two factors while the females' show a weak correlation $(R=-0.145)$ (

Table $1 \&$ Table 2). According to Fig. 2, the growing trend of males' heights with familiarity to exits is similar as that with the satisfaction of the indoor signs. While for the females, this trend is eliminated. The majority of the females in different height groups have similar average level of exit familiarity. On the other hand, this also implies the current height of the indoor signs may not be ideal for all the population, especially for people with lower body heights, i.e. female participants in this survey. This finding also agree with a previous study, which indicates that occupants during the evacuation are less likely to realize the existence of guidance signs at the ceiling level limited by their heights [23]. Meanwhile, the user height does not significantly affect the familiarity to the risky places for both genders, which may be due to par- 
ticipants' ubiquitous lower awareness of this information.

In addition, the knowledge of indoor exits and risky places are also positively correlated with the satisfaction levels of indoor signs (

Table $1 \&$ Table 2). Between these two factors, the familiarity to the exits has stronger impacts, with $R=0.532$ for the females and $R=0.414$ for the males, while $R \approx 0.31$ for indoor risky place awareness for both genders. According to the previous results, there are more females having higher familiarity with the indoor risky places than males. However, this does not significantly affect their satisfactions to the indoor signs, as there is no great difference on $R$ between two genders. This implies that the current indoor signs may not give a very clear guidance of the risky places. On the other hand, the increasing familiarity with the indoor exits signs can lead to the growth of the satisfaction with at least moderate possibility. This suggests that people are more interested in the guidance signs of exits rather than those of the risky places. This also agrees with the findings from the correlation with user heights. Moreover, this hypothesis is supported by the correlation between the familiarity of exits and risky places. This study has assumed that people with higher familiarity with the exits may also be highly familiar with risky places. However, after calculating their correlation coefficients $R$, their relationship seems to be weak with $R=0.27$ for the females and $R=0.21$ for the males (

Table $1 \&$ Table 2).

Table 1. Correlation between Height and Other Indoor Familiarity Factors for Males

\begin{tabular}{llll}
\hline & Height $(\mathrm{cm})$ & Familiarity with Exits & Risk Place Awareness \\
\hline Familiarity with Exits & 0.561 & 1 & \\
Risk Place Awareness & 0.265 & 0.213 & 1 \\
Indoor Signs Satisfaction & 0.559 & 0.414 & 0.315 \\
\hline
\end{tabular}

Table 2. Correlation between Height and Other Indoor Familiarity Factors for Males

\begin{tabular}{llll}
\hline & Height $(\mathrm{cm})$ & Familiarity with Exits & Risk Place Awareness \\
\hline Familiarity with Exits & -0.145 & 1 & \\
Risk Place Awareness & 0.284 & 0.271 & 1 \\
Indoor Signs Satisfaction & 0.311 & 0.532 & 0.314 \\
\hline
\end{tabular}

When integrating the effects from the familiarity of exits and indoor risky places from both genders, their $R$ for indoor sign satisfaction can achieve 0.471 (male) and 0.556 (female), reflecting a strong bonding relationship. In other words, people who are more familiar with the current indoor environment may be potentially more satisfied with the current installation of the indoor environment. However, the familiarity with the selected factors for this experiment is only about the exits and risky places, this may be limited as other indoor infrastructures (e.g. temporary shelters for blocked people) may also be important for the evacuation process. When integrating height factor with the indoor familiarity, the correlations to the indoor sign satisfaction for both genders are stronger than only considering the effects from familiarity to the exits and risky places, with $R=0.562$ for the females and $R=0.479$ for the males. 
When comparing to the previous results, the height has stronger effect for the males as it has a $1.49 \%$ improvement of $R$ while the females only have $1.08 \%$ (Table 3 ). On the contrary, the height factor integrated with the satisfaction to the signs may also help people to familiarize their surrounding environments, supported by the increasing $R$ with the exits and risky places for both genders (Table 4).

Table 3. Correlation between Indoor Satisfaction and Other Indoor Familiarity Factors with and Without the Effect of the Height

\begin{tabular}{|c|c|c|}
\hline & \multicolumn{2}{|c|}{ Indoor Sign Satisfaction } \\
\hline & Male & Female \\
\hline Familiarity with the Exits+ Risk Place Awareness & 0.471 & 0.556 \\
\hline Height+ Familiarity to the Exits+ Risk Place Awareness & 0.479 & 0.562 \\
\hline
\end{tabular}

Table 4. Correlation between Different Indoor Familiarity Factors with and Without the Effect of the Height

\begin{tabular}{lllll}
\hline & Male & \multicolumn{3}{l}{ Female } \\
\hline \multirow{2}{*}{ Factors } & $\begin{array}{l}\text { Familiarity } \\
\text { with Exits }\end{array}$ & $\begin{array}{l}\text { Familiarity with } \\
\text { Risky Places }\end{array}$ & $\begin{array}{l}\text { Familiarity } \\
\text { with Exits }\end{array}$ & $\begin{array}{l}\text { Familiarity with } \\
\text { Risky Places }\end{array}$ \\
\hline Satisfaction to the Signs & 0.41 & 0.31 & 0.53 & 0.31 \\
Height + Satisfaction to the Signs & 0.43 & 0.32 & 0.54 & 0.32 \\
\hline
\end{tabular}

\subsection{Psychological Stress Under Bending Posture}

For the aspect of psychological difficulty, the response distribution of male participants is more polarized. The majority of their responses are clustered at the ' $0 \sim 1$ ' (36\%) and '3 4' (46\%). Meanwhile, the females' responses are more prone to the moderate level in the range of 2 to 3 (54\%) (Fig. 3(a)). However, their average level of hardness sensing are similar, with 2.27 for males and 2.25 for females. For the aspect of nervousness, about $41 \%$ of male participants are considered as vulnerable population with a score at ' $4-5$ ', while only about $36 \%$ of the females have scored at the same range (Fig. 3(b)). However, the females still have a slightly higher average level of nervousness (3.11) than male participants (2.86). This may be explained by the fact that there are still more female participants who have a moderate level of nervousness (score ' 3 ') when using stoop-walking posture while the responses from the male participants tend to be more evenly distributed. This finding is also supported by a previous study that man is more prone to maintain calm during the evacuation [16]. For the aspect of speed reduction sensation, about half of the male interviewees have scored ' 4 ' with an average level of 3.5 , while only about $29 \%$ of female participants have same responses with an average score of 3.29 (Fig. 3(c)). This may be explained by the finding that the females' responses are more evenly distributed while the males' responses are more clustered at '4', showing the male participants with a greater capability of controlling the moving velocity during fire.

These three factors are positively correlated between each other from mid-level to high-level (Table $5 \&$ Table 6). The $R$ between psychological difficulty and nervous- 
ness is much stronger for male participants $(0.74)$ than that for the females $(0.45)$. This may be explained by the influence from the height, as it has a stronger negative impact on males' nervousness $(-0.427)$ than females $(-0.133)$. Moreover, the average height of the males is also higher than that of the females. This hypothesis is further supported by integrating the factors of height and psychological difficulty, as $R$ for both genders has slightly increased and the improvement for the males $(0.54 \%)$ is more significant than that for the females $(0.22 \%)$ (Table 5). The awareness of speed reduction is more positively correlated with the level of nervousness, especially for the females (0.64). This may be due to that psychological stress can affect the cognition of the changing speed [1]. With the growth of the nervousness level, it may be easier to feel the reduction of the moving velocity, though it may not be as significant as that in reality.

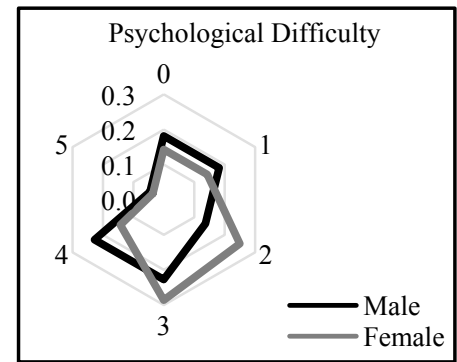

(a)

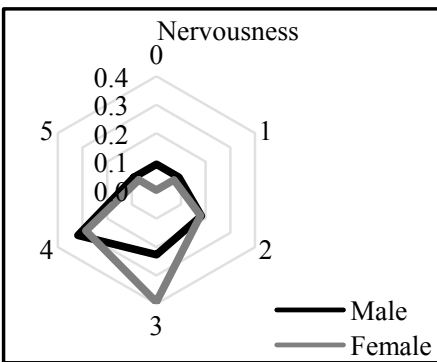

(b)

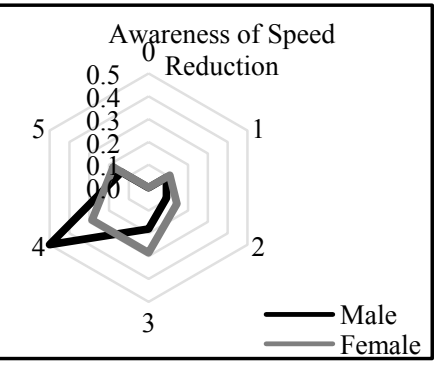

(c)

Fig. 3. The distribution of the feedback of the psychological difficulty (a), nervousness (b) and the awareness feeling of speed (c).

Table 5. Height Effects on Correlation Between Nervousness and Psychological Difficulty

\begin{tabular}{lll}
\hline & \multicolumn{2}{l}{ Nervousness } \\
\hline & Male & Female \\
\hline Psychological Difficulty & 0.741 & 0.450 \\
Height + Psychological Difficulty & 0.745 & 0.451 \\
Improvement & $0.54 \%$ & $0.22 \%$ \\
\hline
\end{tabular}

Table 6. Correlation Among Three Psychological Stress Factors

\begin{tabular}{lll}
\hline & \multicolumn{2}{c}{ Awareness of Speed Reduction } \\
\hline & Male & Female \\
\hline Psychological Difficulty & 0.448 & 0.476 \\
Nervousness & 0.557 & 0.640 \\
Psychological Difficulty + Nervousness & 0.542 & 0.656 \\
Height + Psychological Difficulty + Nervousness & 0.543 & 0.656 \\
\hline
\end{tabular}

On the other hand, panicking people will try to move faster than their normal state, in order to evacuate from the danger as soon as possible [8, 16, 24]. This may lead to a vicious circle as the adage goes 'Faster is slower', because the behaviours such as jamming and stampede may also occur with blocking sights and narrowing paths [24- 
31]. Based on the findings from this study, it may be due to their exaggeration of the speed reduction, leading to lower control of their decision process and action execution. Meanwhile, the level of difficulty perception of using a bending posture also has a moderate impact on the cognition of the velocity reduction, and this impact is more significant for the females. It is understandable as the perception of difficulty may raise the feelings of diffidence and discomfort, exaggerating people's feelings on the speed reductions.

When integrating the impacts from both the psychological difficulty and nervousness level, it can be found that the $R$ to the awareness of speed reduction has become stronger for the females while for the males, it has become slightly weaker. This may be due to the lower level of nervousness from the male participants, which may weaken the effects of the nervousness.

As the height factor can affect the perception of nervousness (Table 5), a hypothesis has been raised that it may also affect the speed reduction perception. However, after integrating the effects from the heights and the other two psychological stresses, their $R$ to speed reduction sensation does not change significantly, especially for the females. It can be inferred that the current level of the height does not have great impacts on speed reduction recognition.

The impacts from the indoor familiarity can be treated as a critical and comprehensive factor for the psychological stress, especially for the level of the nervousness. According to the previous study, one reason for panic is due to the non-efficient using or ignorance of the alternative exits $[1,15,24,32,33]$. On the other hand, the occupants with better indoor familiarity may not be limited to using the shortest routes as people tend to use their familiar routes for evacuation [9, 10, 34]. This study also evaluates the correlations between the factors of different indoor familiarity and psychological stress and the results are shown in Table 7 and Table 8.

Table 7. Correlation between Factors of Indoor Familiarity and Psychological Stress for Males

\begin{tabular}{lllll}
\hline & \multicolumn{3}{c}{ Familiarity Risk Place } & \multicolumn{2}{l}{ Indoor Signs } & Indoor Fa- \\
& with Exits & Awareness & Satisfaction & miliarity \\
\hline Psychological Difficulty & -0.395 & -0.064 & -0.477 & -0.509 \\
Nervousness & -0.293 & -0.151 & -0.431 & -0.432 \\
Awareness of Speed Reduction & 0.262 & -0.015 & -0.176 & $\mathbf{0 . 4 0 1}$ \\
\hline
\end{tabular}

Table 8. Correlation between Factors of Indoor Familiarity and Psychological Stress for Females

\begin{tabular}{lllll}
\hline & \multicolumn{2}{c}{ Familiarity } & Risk Place & Indoor Signs \\
& with Exits & Awareness & Satisfaction & $\begin{array}{l}\text { Indoor Fa- } \\
\text { miliarity }\end{array}$ \\
\hline Psychological Difficulty & 0.187 & 0.074 & 0.049 & 0.172 \\
Nervousness & 0.355 & -0.054 & -0.084 & 0.436 \\
Awareness of Speed Reduction & 0.264 & 0.152 & 0.104 & $\mathbf{0 . 2 5 6}$ \\
\hline
\end{tabular}

According to the acquired results, the hypothesis that the growing familiarity to the exits can help reduce the nervousness is strengthened to some extent based on the 
males' responses. However, the situation for the females is reverse, as their level of nervousness has a moderately positive relationship between the familiarity to the exits. This may be due to the higher average level of indoor familiarity and composure of the male participants as well as different decision process from two genders.

Similar findings can also be found on the sensation of the difficulty as the familiarity to the exits has a moderately negative effect for the males, while having a weakly positive effect for the females. This may be due to the physical limitations of different genders as the females are more easily getting tired using an energy-consuming posture. However, there is no great difference on the impacts of the speed reduction awareness, which is positively related to the familiarity to the exits at a mid-level. This can be explained by the aspiration of escaping from the danger $[8,16,24]$, which may also increase when approaching to the known exits.

As the familiarity with the risk places of both genders is at a low level, its $R$ between each different psychological factor is relatively weak. Meanwhile, the satisfaction to the indoor signs has a mid-level negative effect on the difficulty sensation and the nervousness for the males. While for the females, the strength of $R$ is nearly neglectable. This may be due to the males' relatively higher satisfaction degree to the indoor signs, which can help them better utilize the guidance provided by these signs than the females, leading to decreases on cognitions of difficulty and nervousness.

When integrating all indoor-familiarity factors together to investigate their $R$ between each psychological factors, it can be found out that that males' psychological stresses, such as difficulty and nervousness sensation, may be moderately released with the increasing indoor familiarity, except for the speed reduction awareness. This may be due to the effects from the familiarity to the exits and satisfaction of indoor signs, as males have higher average levels of these two items and a better level of physical abilities. The increasing possibility of speed reduction awareness can be explained by the similar reason mentioned before, i.e. the growing desire of escaping to the outside, which may be affected by the increasing indoor familiarity during the process of moving to the exits. While for the females, their psychological stresses do not follow a similar pattern as the males. All their psychological factors are likely to increase with their growing indoor familiarity, though their $R \mathrm{~s}$ are relatively lower than those for the males. This may be due to their higher average levels of psychological stresses and less knowledge of the indoor environments, as well as their physical limitations, comparing to the males'. Moreover, males have a higher average sensitivity of speed reduction, showing greater controllability of their own moving velocity and lower vulnerability from the other potential factors. Meanwhile, the previous choices of each factor between the two genders have no significant differences $(p>0.05)$, however, when integrating them together into a comprehensive factor, there are significant differences between the choices made by the two genders $(\mathrm{p}<0.01)$. It indicates that the effects from indoor familiarity need to be treated as an entirety before analysing their correlations to the psychological factors.

With the above analyses, it suggests that factors from indoor familiarity are correlated with the psychological effects to some extent, especially on the aspects of the familiarity to all building exits and the satisfaction to the indoor guidance signs. Thus, it suggests that when integrating effects from all the indoor familiarity factors to- 
gether with the impacts from the cognition of difficulty and nervousness, it may have a comprehensive effect on the perception of the speed reduction. The reason of concentrating on the effects to the people's moving velocity is due to that the moving velocity is one of the decisive factors for the establishment of the evacuation models, and it is usually used to evaluate the capability of moving out of the indoor area [1, 35-37]. If the occupants are subject to less than ideal conditions, regardless of the physical or the psychological aspects, this kind of the evacuees can be treated as in a mode with temporarily reduced mobility $[1,37]$, which can affect the process of evacuation to some extent.

When integrating the indoor familiarities with the other two psychological effects, it can be found out that these factors have a slightly greater impact on the awareness of the speed reduction for the female participants $(0.655)$ than that for the males (0.617). This is consistent with the previous findings that the male participants have higher controllability of their speed than the females, although they may still be affected by the effects of the indoor environments. Moreover, the psychological factors have a higher overall impact on the speed reduction awareness than that on the males, while the males' activities are more affected by the indoor environments based on results from

Table 9.

Table 9. Correlation between Factors from Speed Reduction Awareness and Indoor Familiarities plus Psychological Stresses

\begin{tabular}{lll}
\hline & \multicolumn{2}{c}{ Awareness of Speed Reduction } \\
\hline Indoor Familiarity & Male & Female \\
Psychological Difficulty + Nervousness & 0.401 & 0.256 \\
Indoor Familiarity + Psychological Difficulty + Nervousness & 0.617 & 0.656 \\
\hline
\end{tabular}

With the above information, the hypothesis has been proved in this case that the awareness of moving speed reduction during the evacuation will be affected by both environmental and psychological stresses, with a moderately positive $R$. The increase of the environmental familiarity and psychological relief can be achieved by using a personalized and supportive navigation system. This information needs to be considered into the future applications of the smartphone-based emergency guidance as it will affect the user's current psychological state, leading to various choices of the evacuation strategies.

\subsection{Attitude to the Smartphone-based Emergency Guidance}

The Familiarity with the Smartphone-based Navigation Navigation services have been widely used by people around the world in daily life [38, 39]. This study has proposed an assumption that the current smartphone users should be familiar with the smartphone-based navigation. However, the average level of the familiarity (2.64) is not as high as expectation, which is only slightly higher than the mid-level (Fig. 4(a)). This suggests that the participants may have used the navigation services but are still 
not very familiar with its working mechanism. This may be due to the sense of direction, as the guidance provided by the navigation systems still require people to have the capability of spatial cognition [40-43].

When comparing the differences between the two genders, it can be found out that the male participants have a slightly higher average level (2.91) than the females (2.43). This finding also agrees with the previous studies that males usually outperform females on navigation-based tasks [41-43]. This may be due to the different cues utilized by two genders for spatial tasks, as the males prefer identifying the geometric properties and cardinal directions while the females are good at landmark memorization [42-44]. It suggests that the future applications of the smartphone-based emergency navigation may still need some training, especially for the female users.

The Willingness of Following Smartphone Guidance During Evacuation Under Non-Risky Conditions This scenario is regarded as the premise of following guidance under risky conditions. According to the results, the participants of both genders have shown positive attitudes to the emergency navigation app, as none of them shows a rejection (' 0 ') (Fig. 4(b)). This suggests a relatively good acceptance to this kind of service, which can help reduce the difficulty of promoting this service in future applications. The average score of the males (3.41) is still higher than that of the females (3.29), which may be related to the higher familiarity of the male users to the existing smartphone-based navigation. Moreover, the majority of the females (79\%) tend to have an at least mid-level positive attitude ('3-5') to the acceptance of the guidance service, while the choices for the rest of them are more evenly distributed. Meanwhile, about $73 \%$ of the males have an at least mid-level of positive acceptance of using a longer route, with more population having a relatively higher score ('4-5') of the willingness of following the guidance, and the overall distribution of their acceptance level to the navigation is more uniform than that of the females.

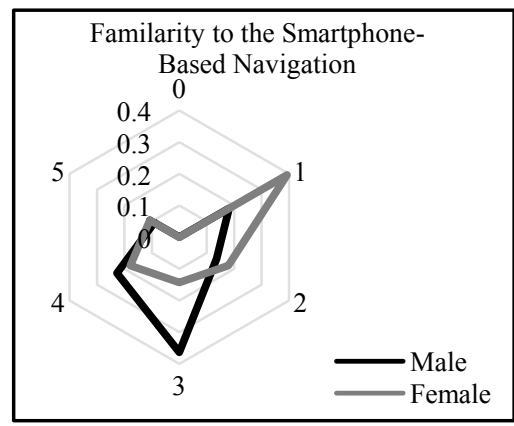

(a)

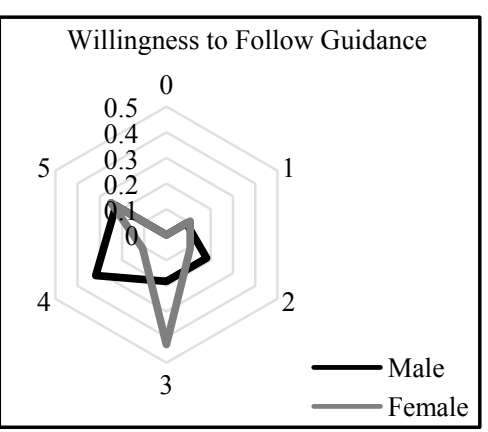

(b)

Fig. 4. The familiarity with the smartphone-based navigation of two genders (a) and the willingness of following the smartphone-based guidance.

The Willingness of Following Smartphone-Based Guidance During Evacuation Under Risky Conditions Although the selected participants have shown positive attitudes to the emergency guidance, it does not mean that they will still do so under 
some extreme conditions. This survey is interested in the user responses when they are required to change from the original planned path when facing the dangers. The two extreme cases selected for this study are the willingness of using a longer path due to risk assessment and changing to an alternative exit during the movement with the original plan. The aim of testing these two cases is to find out the confidence degree of users to the potential guidance under the fire evacuation.

For the first case, the majority of females (86\%) show a positive attitude while there are only $55 \%$ of the males having the confidence of trusting the guidance provided by the smartphones. The corresponding effects may come from three aspects, i.e. indoor familiarity, psychological stress and attitude to the smartphone-based navigation (Table 10). For indoor familiarity, people who are more familiar with indoor structures are more willing to use an alternative but safer path, while the people of the opposite situation may prefer a shorter path $[9,10,34]$. When comparing $R \mathrm{~s}$ between different factors, it can be inferred that psychological stress plays a more important role in the decision of using a longer but safer route, especially for the males. With the increasing psychological stress, people are less likely to use a longer route. This may be due to the psychological stress will affect the decision making during evacuation $[1,3]$, and the average level of the psychological stress of the males is lower than that of the females. The integrated effect from the above two factors moderately contributes to the decision of following a longer but safer route, and this impact is more evident for the males $(0.413)$ than that for the females $(0.350)$. The effect from the acceptance of the smartphone-based navigation is more correlated with the decision of using a longer route for the females, which may be related to males' better performances on geometry identification and lower willingness to use a longer path [42, 43].

Table 10. Correlation between Factors from Willingness of Using A Longer Route and Indoor Familiarities, Psychological Stresses, and Attitude to Navigation

\begin{tabular}{lll}
\hline & \multicolumn{2}{l}{ Willingness of Using A Longer but Safer Path } \\
\hline Indoor Familiarity & Male & Female \\
Psychological Stress & 0.276 & 0.256 \\
Attitude to Navigation & -0.376 & -0.288 \\
Indoor Familiarity + Psychological Stress & 0.187 & 0.269 \\
Indoor Familiarity + Psychological Stress + Attitude to Navigation & 0.413 & 0.428 \\
\hline
\end{tabular}

For the situation of changing to an alternative exit, the percentage of the females showing positive attitudes $(79 \%)$ is not significantly higher than that of the males $(73 \%)$. For the males, their decision is more related with the indoor familiarity while for the female participants, their decision is more affected by the acceptance of the navigation services. This may also due to males' better performances on geometry identification and sensation of the cardinal directions $[42,43]$. This leads to the integrated effects from the indoor familiarity and psychological stress are more correlated with the males' decision of the using an alternative exit (0.377) than females (0.352). After integrating with the effect from attitude to the navigation services, the overall 
comprehensive effects from the three factors shows a greater correlation with the females' decisions (0.515) rather than the males (0.406) (Table 11).

The decision time for different cases is also an important factor to evaluate people's confidence to the provided navigation services. This time period needs be reduced in order to improve the efficiency of the evacuation. According to the acquired results, the females tend to have a longer decision time, regardless of the situations of extreme cases (Fig. 5). It suggests that the females are more hesitated to make decisions under extreme cases. This may be related with their relatively higher level of the psychological stress than the males, leading to the increase of the difficulty of decision making especially for complicated situations. Thus, females may need some additional comforting service to persuade them keep trusting the guidance. Meanwhile, the average time for choosing an alternative exit during evacuation other than the original planning is longer than that of choosing a longer route in the beginning of planning, regardless of the gender. It suggests that changing the direction during the movement is more difficult than making decisions in the beginning and people have the tendency to keep the original guidance during the evacuation movement. This problem needs to considered in the approach design of providing navigation services to people, making the provided information more acceptable to people.

Table 11. Correlation between Factors from Willingness of Using An Alternative Exit and Indoor Familiarities, Psychological Stresses, and Acceptance of Navigation

\begin{tabular}{lll}
\hline & \multicolumn{2}{l}{ The willingness of Using An Alternative Exit } \\
\hline Indoor Familiarity & Male & Female \\
Psychological Stress & 0.311 & 0.265 \\
Attitude to Navigation & -0.301 & -0.243 \\
Indoor Familiarity + Psychological Stress & 0.206 & 0.393 \\
Indoor Familiarity + Psychological Stress + Attitude to Navigation & 0.406 & 0.352 \\
\hline
\end{tabular}

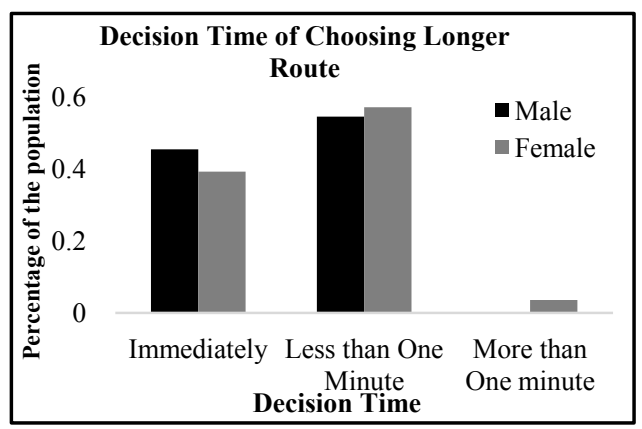

(a)

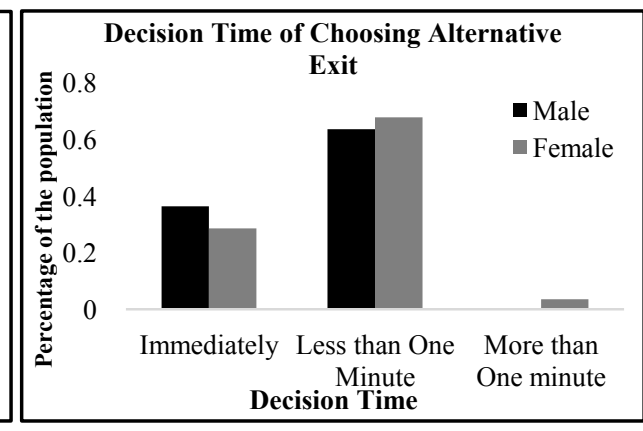

(b)

Fig. 5. The decision time of two genders for choosing longer route (a) and alternative exit (b). 


\section{Conclusions}

This study has taken a survey among the undergraduates to investigate the cognition factors under virtual scenarios in an environment for their routine life, focusing on the aspects of indoor familiarity (spatial cognition), psychological stress and decision makings.

For indoor familiarity, it is interested in three factors, i.e. the familiarity to exits and risky places as well as the satisfaction degree of the current indoor sign installation. According to the results, males have a higher average familiarity to the indoor exits while both genders have a relatively low level of risky place awareness. These two factors are positively correlated with satisfaction degree of current installation of the indoor signs, and this correlation is more evident for the exit familiarity. The integration of the height factor with the other two indoor familiarity factors can improve the degree of the indoor sign satisfaction.

For psychological stress, this study concentrates on the situated cognition of moving difficulty, nervousness, and speed reduction when using a bending posture during the fire evacuation to avoid smoke inhalation. The results have shown that both genders have a similar mid-level hardness sensation. The females have a higher average level of nervousness, while males have a higher average level of speed reduction sensation. This study has assumed that the growing indoor spatial cognition can help ease the psychological hardness and nervousness. However, it only seems to be true after reaching a certain level. When integrating the effects from indoor familiarity and the other two psychological factors, the correlation to the speed reduction sensation can be strengthened.

This study has also investigated the participants' attitudes to the navigation support during evacuation and the majority of the participants have shown positive attitudes. For following the guidance under some extreme cases, i.e. changing to a longer path and to an alternative exit, the majority of the participants has shown the confidence of keeping trusting the guidance service. These decisions are affected by the combined influences from indoor familiarity, psychological stress, and attitude of using navigation service. For the decision time of the selected extreme cases, it costs more time in average for deciding to use a longer route than to use an alternative exit, and this situation is more evident for the female participants. This requires further considerations when designing a personalized smartphone-based navigation app. In future improvements, more scenarios and potential cognition factors can be investigated and be integrated with the simulation results of a fire evacuation, which may help give a more thorough analysis of the effects from the potential cognition factors.

\section{References}

1. M. Kobes, I. Helsloot, B. De Vries, and J. G. Post, "Building safety and human behaviour in fire: A literature review," Fire Safety Journal, vol. 45, pp. 1-11, 2010.

2. M. Kobes, Zelfredzaamheid bij brand: Kritische factoren voor het veilig vluchten uit gebouwen [Fire response performance: the critical factors for a safe escape out of buildings]. Den Haag, The Netherlands: Boom Juridische Uitgevers, 2008. 
3. L. Xiong, D. Bruck, and M. Ball, "Utilization of the Haddon Matrix to organize factors of survived accidental residential fires: frequencies for human, agent, and environmentrelated variables," Fire Safety Science, vol. 11, pp. 1049-1062, 2014.

4. M. Raubal and M. J. Egenhofer, "Comparing the complexity of wayfinding tasks in built environments," Environment and Planning B: Planning and Design, vol. 25, pp. 895-913, 1998.

5. I. Aedo, S. Yu, P. Díaz, P. Acuña, and T. Onorati, "Personalized alert notifications and evacuation routes in indoor environments," Sensors, vol. 12, pp. 7804-7827, 2012.

6. J. Koo, Y. S. Kim, and B.-I. Kim, "Estimating the impact of residents with disabilities on the evacuation in a high-rise building: A simulation study," Simulation Modelling Practice and Theory, vol. 24, pp. 71-83, 2012.

7. M. Manley and Y. S. Kim, "Exitus: Agent-based evacuation simulation for individuals with disabilities in a densely populated sports arena," International Journal of Intelligent Information Technologies (IJIT), vol. 8, pp. 1-13, 2012.

8. A. Trivedi and S. Rao, "Agent-based modeling of emergency evacuations considering human panic behavior," IEEE Transactions on Computational Social Systems, vol. 5, pp. 277-288, 2018.

9. T. Graham and D. Roberts, "Qualitative overview of some important factors affecting the egress of people in hotel fires," International Journal of Hospitality Management, vol. 19, pp. 79-87, 2000.

10. J. Shi, A. Ren, and C. Chen, "Agent-based evacuation model of large public buildings under fire conditions," Automation in Construction, vol. 18, pp. 338-347, 2009.

11. E. D. Kuligowski, "Human behavior in fire," in SFPE Handbook of Fire Protection Engineering, ed: Springer, 2016, pp. 2070-2114.

12. M. Mohan, P. Sridhar, and S. Srinath, "SMART Evacuation System," International Journal for Research in Applied Science \& Engineering Technology (IJRASET), vol. 4, pp. 681685, March 20162016.

13. [13] B. E. Aguirre, "Emergency evacuations, panic, and social psychology," Psychiatry: Interpersonal and Biological Processes, vol. 68, pp. 121-129, 2005.

14. J. Drury, D. Novelli, and C. Stott, "Psychological disaster myths in the perception and management of mass emergencies," Journal of Applied Social Psychology, vol. 43, pp. 2259-2270, 2013.

15. P. Sarshar, J. Radianti, and J. J. Gonzalez, "Modeling panic in ship fire evacuation using dynamic Bayesian network," in Third International Conference on Innovative Computing Technology (INTECH 2013), 2013, pp. 301-307.

16. J.-Q. Shen, X.-W. Wang, and L.-L. Jiang, "The influence of panic on the efficiency of escape," Physica A: Statistical Mechanics and its Applications, vol. 491, pp. 613-618, 2018.

17. R. Grasso, M. Zago, and F. Lacquaniti, "Interactions between posture and locomotion: motor patterns in humans walking with bent posture versus erect posture," Journal of Neurophysiology, vol. 83, pp. 288-300, 2000.

18. M. Hora, V. Sládek, L. Soumar, and T. Michálek, "Influence of body mass and lower limb length on knee flexion angle during walking in humans," Folia Zoologica, vol. 61, pp. 330340, 2012.

19. M. Hora and V. Sladek, "Influence of lower limb configuration on walking cost in Late Pleistocene humans," Journal of human evolution, vol. 67, pp. 19-32, 2014.

20. M. Hora, L. Soumar, H. Pontzer, and V. Sládek, "Body size and lower limb posture during walking in humans," PloS one, vol. 12, p. e0172112, 2017.

21. W. W. Campbell, DeJong's The neurologic examination, 7th Edition. Philadelphia: Lippincott Williams \& Wilkins, 2013. 
22. J. D. Brown, "Significance of Posture in Relation to Falls in the Elderly," Ashland University, 2017.

23. C. Johnson, "Lessons from the evacuation of the world trade centre, $9 / 112001$ for the development of computer-based simulations," Cognition, Technology \& Work, vol. 7, pp. 214-240, 2005.

24. D. Helbing, I. Farkas, and T. Vicsek, "Simulating dynamical features of escape panic," Nature, vol. 407, p. 487, 2000.

25. A. R. Mawson, "Understanding mass panic and other collective responses to threat and disaster," Psychiatry: Interpersonal and biological processes, vol. 68, pp. 95-113, 2005.

26. M.-B. Hu, W.-X. Wang, R. Jiang, Q.-S. Wu, and Y.-H. Wu, "The effect of bandwidth in scale-free network traffic," EPL (Europhysics Letters), vol. 79, p. 14003, 2007.

27. M.-B. Hu, R. Jiang, Q.-S. Wu, and Y.-H. Wu, "Simulating the wealth distribution with a Richest-Following strategy on scale-free network," Physica A: Statistical Mechanics and its Applications, vol. 381, pp. 467-472, 2007.

28. D. R. Parisi and C. O. Dorso, "Morphological and dynamical aspects of the room evacuation process," Physica A: Statistical Mechanics and its Applications, vol. 385, pp. 343-355, 2007.

29. S. A. Soria, R. Josens, and D. R. Parisi, "Experimental evidence of the "Faster is Slower" effect in the evacuation of ants," Safety science, vol. 50, pp. 1584-1588, 2012.

30. K. Suzuno, A. Tomoeda, and D. Ueyama, "Analytical investigation of the faster-is-slower effect with a simplified phenomenological model," Physical Review E, vol. 88, p. 052813, 2013.

31. Z. Shahhoseini, M. Sarvi, and M. Saberi, "Pedestrian crowd dynamics in merging sections: Revisiting the "faster-is-slower" phenomenon," Physica A: Statistical Mechanics and its Applications, vol. 491, pp. 101-111, 2018.

32. N. Shiwakoti and M. Sarvi, "Understanding pedestrian crowd panic: a review on model organisms approach," Journal of transport geography, vol. 26, pp. 12-17, 2013.

33. L. Benthorn and H. Frantzich, "Fire alarm in a public building: How do people evaluate information and choose an evacuation exit?," Fire and Materials, vol. 23, pp. 311-315, 1999.

34. L. Tan, M. Hu, and H. Lin, "Agent-based simulation of building evacuation: Combining human behavior with predictable spatial accessibility in a fire emergency," Information Sciences, vol. 295, pp. 53-66, 2015.

35. J. D. Sime, "An occupant response shelter escape time (ORSET) model," Safety science, vol. 38, pp. 109-125, 2001

36. M. Kobes, "Een bouwkundig perspectief op evacuatie uit gebouwen [An architectural perspective on building evacuation]," in Zelfredzaamheid en fysieke veiligheid van burgers: verkenningen [Resillience and physical safety of citizens: explorations]. R. Van den Brand, M. Duyvis, and M. Kobes, Eds., ed Nibra, Arnhem: Nibra Publicatiereeks, 2005.

37. E. Oomes, "Mobiliteit [Mobility]," Article in:'Ome Ed, 2006.

38. J. Bao, Y. Zheng, D. Wilkie, and M. Mokbel, "Recommendations in location-based social networks: A survey," GeoInformatica, vol. 19, pp. 525-565, 2015.

39. F. Bentley, H. Cramer, and J. Müller, "Beyond the bar: The places where location-based services are used in the city," Personal and Ubiquitous Computing, vol. 19, pp. 217-223, 2015.

40. R. P. Darken, T. Allard, and L. B. Achille, "Spatial orientation and wayfinding in largescale virtual spaces: An introduction," Presence: Teleoperators and Virtual Environments, vol. 7, pp. 101-107, 1998. 
41. D. C. Geary, S. J. Saults, F. Liu, and M. K. Hoard, "Sex differences in spatial cognition, computational fluency, and arithmetical reasoning," Journal of Experimental child psychology, vol. 77, pp. 337-353, 2000.

42. C. M. Jones and S. D. Healy, "Differences in cue use and spatial memory in men and women," Proceedings of the Royal Society B: Biological Sciences, vol. 273, pp. 22412247, 2006.

43. M. de Goede, Gender differences in spatial cognition: Utrecht Un iversity, 2009.

44. G. He, T. Ishikawa, and M. Takemiya, "Collaborative Navigation in an Unfamiliar Environment with People Having Different Spatial Aptitudes," Spatial Cognition \& Computation, vol. 15, pp. 285-307, 2015/10/02 2015. 